\title{
Congenital Erythropoietic Porphyria: Identification and Expression of 10 Mutations in the Uroporphyrinogen III Synthase Gene
}

\author{
Weiming Xu, Cecilia A. Warner, and Robert J. Desnick \\ Department of Human Genetics, Mount Sinai School of Medicine, New York 10029
}

\begin{abstract}
To investigate the molecular basis of the phenotypic heterogeneity in congenital erythropoietic porphyria, the mutations in the uroporphyrinogen III synthase gene from unrelated patients were determined. Six missense (L4F, Y19C, V82F, V99A, A104V, and G225S), a nonsense (Q249X), a frameshift (633insA), and two splicing mutations (IVS2 ${ }^{+1}$ and IVS9 ${ }^{\Delta \mathrm{A}+4}$ ) were identified. When L4F, Y19C, V82F, V99A, A104V, 633insA, G225S, and Q249X were expressed in Escherichia coli, only the V82F, V99A, and A104V alleles expressed residual enzymatic activity. Of note, the V82F mutation, which occurs adjacent to the $5^{\prime}$ donor site of intron 4 , resulted in $\sim 54 \%$ aberrantly spliced transcripts with exon 4 deleted. Thus, this novel exonic single-base substitution caused two lesions, a missense mutation and an aberrantly spliced transcript. Of the splicing mutations, the IVS2 $^{+1}$ allele produced a single transcript with exon 2 deleted, whereas the IVS9 ${ }^{\Delta \mathrm{A}+4}$ allele was alternatively spliced, $\sim 26 \%$ being normal transcripts and the remainder with exon 9 deleted. The amount of residual activity expressed by each allele provided a basis to correlate genotype with disease severity, thereby permitting genotype/phenotype predictions in this clinically heterogeneous disease. (J. Clin. Invest. 1995. 95:905-912.) Key words: porphyria - uroporphyrinogen III synthase $\bullet$ uroporphyrinogen I $\bullet$ mutation detection • prokaryotic expression
\end{abstract}

\section{Introduction}

Congenital erythropoietic porphyria (CEP), ${ }^{1}$ also known as Günther disease, is an inborn error of heme biosynthesis resulting from the markedly deficient activity of the fourth en-

Address correspondence to R. J. Desnick, Professor and Chairman, Department of Human Genetics, Mount Sinai School of Medicine, Fifth Avenue and 100th Street, New York 10029. Phone: 212-241-6944; FAX: 212-360-1809.

Received for publication 27 September 1994 and in revised form 1 November 1994.

1. Abbreviations used in this paper: CEP, congenital erythropoietic porphyria; nt, nucleotide; RT, reverse transcriptase; URO I, uroporphyrin I; URO-synthase, uroporphyrinogen III synthase.

J. Clin. Invest.

(c) The American Society for Clinical Investigation, Inc. 0021-9738/95/02/0905/08 \$2.00

Volume 95, February 1995, 905-912 zyme of the heme biosynthetic pathway, uroporphyrinogen III synthase (URO-synthase; EC 4.2.1.75), and the accumulation of the nonphysiologic uroporphyrin I (URO I) isomer (1-3). In patients with this autosomal recessive disease, the clinical manifestations are markedly heterogeneous, ranging from nonimmune hydrops fetalis to milder, later onset forms which have only cutaneous lesions in adult life $(1,2,3-6)$. Severely affected patients are transfusion dependent throughout life, have secondary hypersplenism, and are usually disfigured due to the cutaneous involvement. Additional manifestations may include hypertrichosis, alopecia, and erythrodontia. Although milder patients have some residual activity to synthesize sufficient heme for hematopoiesis and for other essential heme-requiring proteins, the amount of residual activity appears to be correlated with clinical severity $(7,8)$.

URO-synthase normally catalyzes the conversion of the linear tetrapyrrole, hydroxymethylbilane, to uroporphyrinogen III, the physiologic cyclic isomer which is metabolized in subsequent enzymatic steps to heme $(9,10)$. The markedly deficient activity of URO-synthase results in the nonenzymatic conversion of hydroxymethylbilane to the uroporphyrinogen I isomer, which is then oxidized to the nonphysiologic and pathogenic compound, URO I. Excessive URO I in erythrocytes leads to hemolysis and the released porphyrin isomer is deposited in tissues and bones and is excreted in the urine and feces. Light activates the photocatalytic URO I resulting in tissue damage and the formation of bullous lesions which rupture, often becoming infected, leading to bone resorption and cutaneous deformity $(11-14)$.

Human URO-synthase has been purified to homogeneity from erythrocytes and shown to be a monomeric protein with an apparent molecular mass of $29.5 \mathrm{kD}$ (15). Recently, the fulllength cDNA encoding the human URO-synthase polypeptide of 265 amino acids was isolated, sequenced, and expressed in Escherichia coli (16). Using the cDNA as a probe, a single URO-synthase gene was assigned to the narrow chromosomal region, 10q25.3 $\rightarrow \mathrm{q} 26.3$ (17). Analysis of the URO-synthase genomic sequence revealed 10 exons, and the sequence of each exon-intron junction has been determined (7). The availability of the URO-synthase cDNA permitted investigation of the molecular lesions causing CEP. To date, six missense mutations $(7,8,18-20)$, an 80-bp insertion, and a 98-bp deletion (del148-245) (20) have been identified in unrelated CEP patients. Of note, only the C73R lesion was common, occurring in about one third of the CEP alleles studied, whereas the other mutations were detected only in one to three unrelated families $(7,8,18-20)$. Each of the missense mutations has been expressed in $E$. coli $(8,20)$, and several were found to have significant residual activity which appeared to correlate with milder phenotypes $(7,8,20)$. 
Table I. Conditions and Primer Sets for Amplification and Sequencing of URO-Synthase Exons

\begin{tabular}{|c|c|c|c|}
\hline Primer Set & $\begin{array}{l}\text { URO-synthase cDNA } \\
\text { sequence amplified }\end{array}$ & Oligonucleotide primer & Annealing condition $\left({ }^{\circ} \mathrm{C} ; \mathrm{min}\right)$ \\
\hline 1 & $-196-(-27)$ & $\begin{array}{l}\text { a. 5'-Bgcgcagccacccacgagaccccagtctgaggtg-3' } \\
\text { b. } 5^{\prime} \text {-actgtgtcacacaccgccggccgggcccct-3' } \\
\text { c. 5'-ccgcgggcttcggcgtcgta-3' }\end{array}$ & $58 ; 1.0$ \\
\hline 2 & $-26-63$ & $\begin{array}{l}\text { a. 5'-Bgataggtctcttccacaag-3' } \\
\text { b. 5'-ACTACT(GAATTC)tttattctgcgtcagttcc-3' } \\
\text { c. 5'-gtttgcaaaacccatcc-3' }\end{array}$ & $51 ; 1.0$ \\
\hline 3 & $64-147$ & $\begin{array}{l}\text { a. 5'-Bggtttgcaaaacctcaga-3' } \\
\text { b. 5'-ACTACT(GAATTC)gtaagttatgetgccatgt-3' } \\
\text { c. 5'-ACTACT(GAATTC)gtaagttatgctgccatgt-3' }\end{array}$ & $51 ; 1.0$ \\
\hline 4 & $148-244$ & $\begin{array}{l}\text { a. } 5^{\prime} \text {-ttggagctgccacgcggtgg-3' } \\
\text { b. } 5^{\prime} \text {-Bctgggagtttaggagatag-3' } \\
\text { c. } 5^{\prime} \text {-gctgcagaattctgagtctt-3' }\end{array}$ & $58 ; 1.0$ \\
\hline 5 & $245-319$ & $\begin{array}{l}\text { a. 5'-Batagtttgctttgctcacag-3' } \\
\text { b. 5'-ACTACT(GAATTC)ctgcattcttatcagtag-3' } \\
\text { c. 5'-taaactgagttaaactgtt-3' }\end{array}$ & $50 ; 1.0$ \\
\hline 6 & $320-394$ & $\begin{array}{l}\text { a. 5'-Batacctgtgtatttgcacgt-3' } \\
\text { b. 5'-ACTACT(GAATTC)caagaatgcactgaggaaa-3' } \\
\text { c. 5'-ACTACT(GAATTC)caagaatgcactgaggaaa-3' }\end{array}$ & $50 ; 0.5$ \\
\hline 7 & $395-475$ & $\begin{array}{l}\text { a. 5'-Bctgagtcctagaagcagag-3' } \\
\text { b. 5'-ACTACT(GAATTC)cacccacttctatcactgc-3' } \\
\text { c. 5'-cacttctatcactgcaa-3' }\end{array}$ & $50 ; 0.5$ \\
\hline 8 & $476-561$ & $\begin{array}{l}\text { a. 5'-Baggagggtggtgctgtatt-3' } \\
\text { b. 5'-ACTACT(GAATTC)gggacagtgaaaccacata-3' } \\
\text { c. 5'-acatctatcagctcgtgccttgaccet-3' }\end{array}$ & $52 ; 1.0$ \\
\hline 9 & $562-660$ & $\begin{array}{l}\text { a. 5'-Bttggtggcctgtggcttga-3' } \\
\text { b. 5'-ACTACT(GAATTC)taaggcacctgctaggcca-3' } \\
\text { c. 5'-ggcttgaggtcttgatgcggat-3' }\end{array}$ & $52 ; 1.0$ \\
\hline 10 & $661-1083$ & $\begin{array}{l}\text { a. 5'-Bcgtcacatgagcagtaacg-3' } \\
\text { b. 5'-ACTACT(GAATTC)atagtctcctccetg-3' } \\
\text { c. 5'-atgcctggctccatccag-3' }\end{array}$ & $52 ; 1.0$ \\
\hline
\end{tabular}

Oligonucleotides a, b, and c indicate primers for sense and antisense amplification and for sequencing, respectively. EcoRI recognition sites are in parentheses. Underlined nucleotides represent additional non-URO-synthase sequence to facilitate restriction enzyme cleavage. B indicates biotinylated nucleotide.

In this communication, a rapid sequencing technique was used to analyze all 10 exons from 20 unrelated CEP patients (21). 10 new mutations (L4F, Y19C, V82F, V99A, A104V, G225S, Q249X, 633insA, IVS2 ${ }^{+1}$, and IVS9 ${ }^{\Delta A+4}$ ) and four of the previously reported missense mutations were identified. Expression of the new missense, nonsense, and frameshift mutations revealed that only V82F, V99A, and A104V had detectable residual activity, and that IVS2 ${ }^{+1}$, IVS $9^{\triangle \mathrm{A}+4}$, and V82F altered splicing of the normal transcript. Notably, the levels of residual activity expressed by both mutant alleles were correlated with disease severity. These studies document the molecular heterogeneity in CEP and demonstrate the usefulness of expression studies for genotype/phenotype correlations.

\section{Methods}

Patient specimens and severity classification. Peripheral blood samples were collected from 20 unrelated CEP patients and their family members with informed consent. Lymphoid cell lines were established using cyclosporin A and Epstein-Barr virus as previously described (22). Cells were maintained by standard procedures in RPMI 1640 media supplemented with $10 \%$ heat-inactivated fetal bovine serum, $1 \%$ penicillin, and $1 \mathrm{mg} / \mathrm{ml}$ of streptomycin (Gibco Laboratories, Grand Island, NY). Patients who developed nonimmune hydrops fetalis and/or were transfusion dependent at any age were classified as severe. Transfusionindependent patients were classified as moderate or mild depending on their age, hematologic indices, splenic size, and/or extent and severity of their cutaneous lesions.

Detection of URO-synthase mutations. Genomic DNA was extracted from lymphoblasts (23) and each exon, including its intron/exon boundaries, was amplified by the polymerase chain reaction (24) using primer sets in which one primer was biotinylated as indicated in Table I. Each $50-\mu \mathrm{l}$ amplification reaction contained $2 \mu \mathrm{g}$ of genomic DNA, $20 \mathrm{pmol}$ of each primer, $10 \mathrm{nM}$ of each dNTP, $50 \mathrm{mM}$ Tris-HCl, pH 9.0, 50 $\mathrm{mM} \mathrm{NaCl}, 10 \mathrm{mM} \mathrm{MgCl}$, and $2 \mathrm{U}$ of Taq polymerase (Promega Biotec Madison, WI). After an initial 5-min incubation at $94^{\circ} \mathrm{C}$, amplification ( 30 cycles) was performed with denaturation at $94^{\circ} \mathrm{C}$ for $1 \mathrm{~min}$, extension at $72^{\circ} \mathrm{C}$ for $0.5 \mathrm{~min}$, and annealing at the indicated conditions for each primer set (Table I). An aliquot $(40 \mu \mathrm{l})$ of each amplification product was incubated with $40 \mu \mathrm{l}$ of streptavidin-coated paramagnetic 
beads (Dynabeads M-280 Streptavidin; Dynal, Inc., Lake Success, NY) for 30 min with occasional gentle mixing. Beads with bound biotinylated PCR products were separated with a magnet as described (25), the strands were denatured in $10 \mu \mathrm{l}$ of $0.1 \mathrm{M} \mathrm{NaOH}$ for $30 \mathrm{~min}$, and the nonbiotinylated strands were eluted with two $50-\mu \mathrm{l}$ washes of $0.1 \mathrm{M}$ $\mathrm{NaOH}$. The biotinylated strands were washed with $50 \mu \mathrm{l}$ of the binding and washing buffer $(10 \mathrm{mM}$ Tris- $\mathrm{HCl}, \mathrm{pH} 7.5$, containing $1.0 \mathrm{mM}$ EDTA and $2.0 \mathrm{M} \mathrm{NaCl}$ ) and then with $50 \mu \mathrm{l}$ of Tris-EDTA buffer. The biotinylated strands were resuspended in $7 \mu \mathrm{l}$ of $\mathrm{H}_{2} \mathrm{O}$ and used as templates for dideoxy chain sequencing (26). The sequencing gels were loaded with the $C$ (and then $T, A$, and $G$ ) reactions from a series of patients in adjacent wells so that the nucleotide sequence could be rapidly read by pattern recognition and mutations could be easily identified (see Fig. 1).

Prokaryotic expression and characterization of URO-synthase mutations. The normal and mutant URO-synthase alleles were expressed in $E$. coli using the pKK223-3 vector (Pharmacia LKB Biotechnology, Inc., Piscataway, NJ) as previously described $(8,16)$. pKK-UROSV99A, pKK-UROS-A104V, pKK-UROS-633insA, and pKK-UROSG225S were constructed by cassette substitution of the cloned mutant cDNA into the pKK-UROS vector (8), while the pKK-UROS-L4F, pKK-UROS-Y19C, pKK-UROS-V82F, pKK-UROS-Q249X constructs were engineered by mega-primer PCR mutagenesis (27), and then were cassette-substituted into the pKK-UROS vector.

For construction of pKK-UROS-V99A, sense primer CW153 corresponding to nucleotide (nt) 385-294 of the URO-synthase cDNA with the underlined $T$ to $C$ transition at nt 296 ( $5^{\prime}$-tatattctgcaagcttttctgc atttccacaggttctccttctgtatccaggccaattttactcactagaagcagtagcatttccagcc$\left.3^{\prime}\right)$ and antisense primer WX19 corresponding to nt 73-92 of UROsynthase cDNA ( $5^{\prime}$-ttatatggacttgaagccac- $3^{\prime}$ ) were used to amplify pKKUROS. The amplification product was digested with HindIII and the 225-nt HindIII fragment was used as a cassette to replace the corresponding fragment in pKK-UROS. pKK-UROS-A104V was similarly constructed except that primer CW155, which corresponded to nt 385310 with the underlined $C$ to $T$ transition at nt 311 ( $5^{\prime}$-tatattctgcaagcttttctgcatttccacaggtttctcettctgtatccaggccaattttactcactagagaaac- $3^{\prime}$ ), was used in place of primer CW153. For pKK-UROS-633ins $\bar{A}$, sense primer CW131 (5'-ggcgcggaattcccggggatccgtcgacctgcagccaagctgtcccgcgagtgccc- $3^{\prime}$ ), which corresponded to $35 \mathrm{bp}$ of the polycloning site of the pKK223-3 vector, the adjacent 15 bp of the URO-synthase cDNA, and an additional 6-bp non-pKK-UROS sequence at its $5^{\prime}$ end, was used with antisense primer WX11 (5'-aacttaatttgatcgatattgtcaccagattaactcctgaatg- $3^{\prime}$ ), which correspond to nt 642-621 of URO-synthase cDNA and had the underlined insertion of an A after nt 633, was used to amplify pKK-UROS. The amplification product was digested with $\mathrm{ClaI}$ and then EcoRI, and the 717-nt fragment was cassette inserted into pKK-UROS. pKK-UROS-G225S was made by replacing the ClaIBsu36I fragment with a cassette generated by amplification of pKKUROS using sense primer WX12, corresponding to nt 628-673 with the underlined $\mathrm{G}$ to $A$ transition at nt 673 (5'-gagttatctggtgacaatatcgatcaaattaagtttgcagccatca- $\left.3^{\prime}\right)$, and antisense primer WX18 ( $5^{\prime}$-accgcttctgcgttctgatt-3') which annealed to the pKK223-3 vector sequence downstream of the HindIII subcloning site.

The mega-primer procedure (27) was used to engineer the following expression constructs. For pKK-UROS-L4F, the sense primer CW131 and antisense primer CW71 coresponding to nt $381-357$ of the UROsynthase cDNA ( 5 '-ttctgcaagctttctgcatttcca- 3 ') were used to amplify a 422-nt URO-synthase cDNA sequence containing the L4F mutation. The 422-nt PCR product was gel purified and used as a mega-primer to amplify the URO-synthase cDNA with antisense primer WX15, which corresponded to nt 728-701 of the URO-synthase cDNA ( 5 '-gcagtgcagcttacaggaaggccctggg-3'). The final 769-nt PCR product was digested with ClaI and EcoRI, and the resulting 717-nt fragment was cassette inserted into pKK-UROS. For pKK-UROS-Y19C, sense primer CW131 and antisense primer CW163, which corresponded to nt 10255 with the underlined $A$ to $G$ transition at $n t 56$ ( $5^{\prime}$-agggatcaaagtggcttcaagtccatataatcctaattccctgatac- $3^{\prime}$ ), were used to amplify the URO-synthase cDNA to generate the mega-primer, which was then used to am- plify the URO-synthase cDNA with antisense primer WX15. The final PCR product was digested with ClaI and EcoRI, and the 717-nt fragment was cassette inserted into pKK-UROS. For pKK-UROS-V82F, the mega-primer was generated by amplification of URO-synthase cDNA with sense primer WX4, which corresponded to nt 222-246 with the underlined $G$ to $T$ transversion at nt 244 ( $5^{\prime}$-ggagcagcaaaacaataaaactgaattc-3') and antisense primer CW71. The mega-primer was used with sense primer CW131 to amplify the URO-synthase CDNA, and the 422nt product was digested with HindIII. The liberated 225-nt fragment was then cassette inserted into pKK-UROS.

For expression, each construct was used to transform of $E$. coli strain JM109. Single colonies were isolated and the inserts were completely sequenced to confirm the engineered sequence and the absence of PCR errors. Bacterial growth, isopropylthiogalactoside induction, and UROsynthase assays were performed as previously described $(8,16)$. For enzyme stability studies, samples from the bacterial lysates, equalized for enzymatic activity, were incubated at $37^{\circ} \mathrm{C}$ in the presence of 0.5 $\mathrm{mg} / \mathrm{ml}$ of bovine serum albumin (Sigma Chemical Co., St. Louis, MO) for $60 \mathrm{~min}$. Aliquots were removed at timed intervals, placed on ice, and the URO-synthase activity was determined by the coupled assay (16).

Analysis of splicing mutations. To determine the presence of stable, aberrantly spliced transcripts for the IVS2 ${ }^{+1}$, IVS9 ${ }^{\Delta A+4}$, and V82F alleles, mRNA was isolated from the respective lymphoid cell line using the FastTrack ${ }^{\mathrm{TM}}$ mRNA Isolation Kit version 3.6 (Invitrogen, San Diego, CA) and reverse-transcribed with Moloney murine leukemia virus reverse-transcriptase (RT) according to manufacturer's instructions (New England Biolabs, Inc., Beverly, MA), using as primer the antisense oligonucleotide CW129 (5'-atgcctggctccatccag-3'), which is complementary to nt 866-849 of the URO-synthase cDNA. The 937 bp URO-synthase RT product was then PCR-amplified (24) with sense primer WX169 (5'-gcagcttttcgctgggactgcgcgacacc-3') and antisense primer WX174 ( $5^{\prime}$-atggggccagcgctaggtggctgac- $3^{\prime}$ ), which annealed to nt 114-84 and nt 823-799 of the URO-synthase cDNA, respectively. The amplification reaction $(100 \mu \mathrm{l})$ contained $2 \mu \mathrm{l}$ of the URO-synthase RT-PCR product, $100 \mathrm{pmol}$ of each primer, $10 \mathrm{nmol}$ of each dNTP, 50 $\mathrm{mM}$ Tris- $\mathrm{HCl}, \mathrm{pH} 9.0,50 \mathrm{mM} \mathrm{NaCl}, 10 \mathrm{mM} \mathrm{MgCl}_{2}$, and $2 \mathrm{U}$ of Taq polymerase (Promega Biotec). After an initial $5 \mathrm{~min}$ incubation at $94^{\circ} \mathrm{C}$, amplification ( 30 cycles) was performed with denaturation at $94^{\circ} \mathrm{C}$ for $1 \mathrm{~min}$, annealing at $60^{\circ} \mathrm{C}$ for $1 \mathrm{~min}$, and extension at $72^{\circ} \mathrm{C}$ for $1 \mathrm{~min}$. The RT-PCR products were electrophoresed in $1 \%$ low melting point agarose gels. The normal and abnormally sized bands were gel purified using the Wizard ${ }^{\mathrm{TM}}$ PCR Preps DNA purification system (Promega Biotec) and sequenced with an Exo( -$) P f u$ Cyclist ${ }^{\mathrm{TM}}$ DNA Sequencing Kit (Stratagene, La Jolla, CA), according to the respective manufacturer's instructions.

The relative amount of the normally and abnormally spliced transcripts for the IVS2 ${ }^{+1}$, IVS $9^{\triangle A+4}$, and V82F alleles were determined as follows. For the IVS2 ${ }^{+1} / \mathrm{L} 4 \mathrm{~F}$ genotype, the URO-synthase RT-PCR products were amplified using antisense primer WX3 (5'-caggatgagaaagcttctca-3'), which anneals to nt 141-160 of URO-synthase cDNA, and sense primer WX173 (5'-tgccctataaggactgccaggcaataatgaaggtc- $\left.3^{\prime}\right)$, which annealed to nt $-26-9$ of URO-synthase cDNA, and contained the underlined $\mathrm{T}$ to $\mathrm{C}$ mismatch that created an Avall restriction site in the PCR product derived from the normal transcript. The 186-bp PCR product was gel purified as above, digested with Avall (New England Biolabs, Inc.), and electrophoresced in a $2 \%$ agarose gel. For the IVS9 ${ }^{\Delta \mathrm{A}+4} /$ IVS $^{\Delta \mathrm{A}+4}$ genotype, the RT-PCR reaction was performed as described above using sense and antisense primers WX169 and WX174, respectively, except that $10 \mathrm{mCi}$ of $\alpha-{ }^{32} \mathrm{P}$-dCTP was added to each amplification reaction. The normal and abnormal bands were individually gel purified, the mean radioactivity of each (normalized for the number of cytosine residues) was determined using a model 1219 RackBeta Liquid Scintillation Counter (Pharmacia LKB Nuclear, Gaithersburg, MD). For the L4F/V82F genotype, the URO-synthase RT-PCR product was amplified in the presence of $10 \mathrm{mCi}$ of $\alpha-{ }^{35} \mathrm{~S}-\mathrm{dATP}$ with sense primer WX19 $\left(5^{\prime}\right.$-ttatatggacttgaagccac- $\left.3^{\prime}\right)$ and antisense primer WX17 (5'-ggttcccttggattcctggg- $\left.3^{\prime}\right)$, which anneal to nt 73-92 and nt 


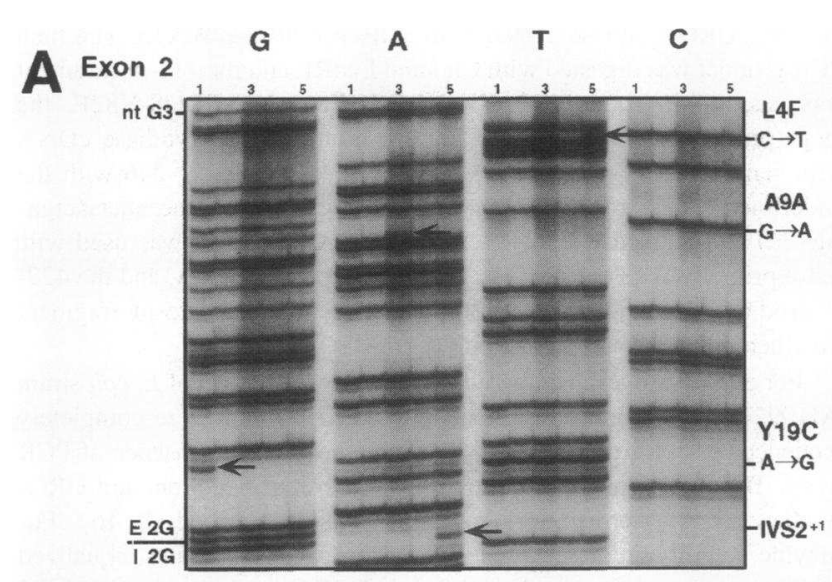

B
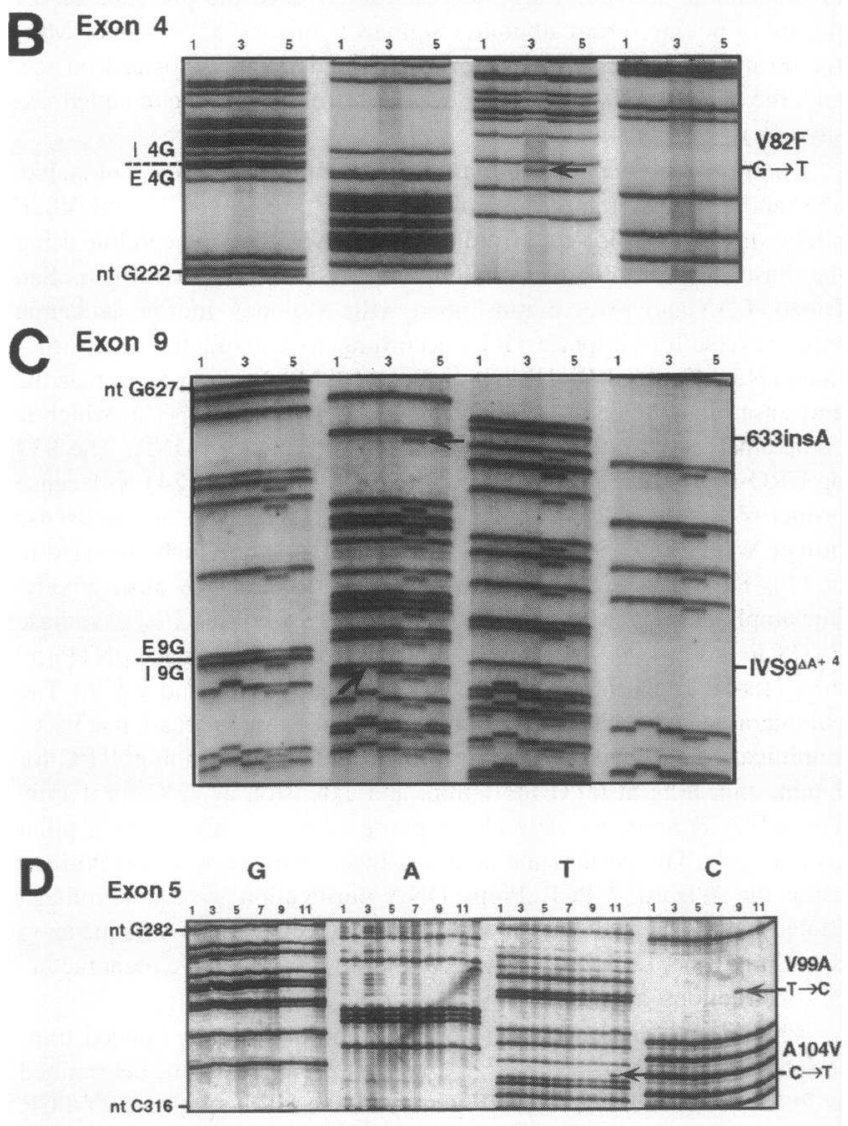

E

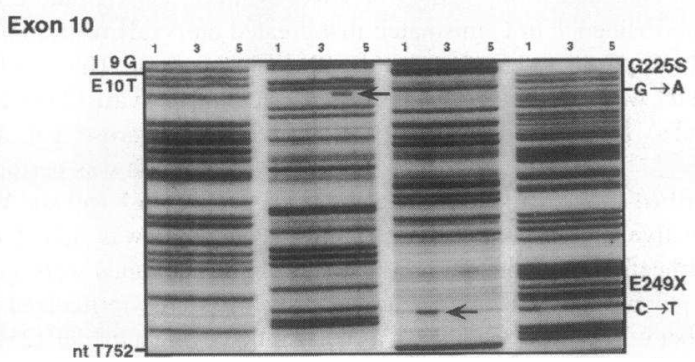

Figure 1. Rapid identification of mutations in the URO-synthase gene by pattern recognition. Partial DNA sequences of amplified URO-synthase genomic DNA showing: $(A)$ three exon 2 lesions and a splicing defect, a $\mathrm{C}$ to $\mathrm{T}$ transition of nt $10(L A F)$, a G to A transition of nt 27
519-538 of the URO-synthase cDNA, respectively. The radioactive PCR products were purified as above, digested with EcoRI (New England Biolabs, Inc.) which recognizes only the V82F allele, and then electrophoresed in a $1.5 \%$ agarose gel. The PCR product and digestion fragments were gel purified, and the radioactivity of each was measured and normalized for the number of adenine residues as above.

\section{Results}

Identification of the URO-synthase mutations. Each of the URO-synthase exons and their respective intron/exon junctions were amplified from the genomic DNAs of 20 unrelated CEP patients using biotinylated primers for rapid strand separation and single-strand solid phase sequencing. As shown in Fig. 1, the individual dideoxy chain sequencing reactions (e.g., $C, A$, $T$, of $G$ ) for a series of patients were run side by side, permitting rapid identification by deviations from the normal pattern of point mutations (e.g., Fig. 1, exon 2) as well as small or large insertions and deletions (e.g., Fig. 1, exon 9). Using this technique, URO-synthase mutations in each of the 20 unrelated patients were identified (Table II). The 10 new mutations included: six missense mutations, a $\mathrm{C}$ to $\mathrm{T}$ transition of $\mathrm{nt} 10$ that predicted a leucine to phenylalanine substitution at residue 4 (designated L4F), an A to $\mathrm{G}$ transition of nt 56 that predicted a tyrosine to cysteine replacement at residue 19 (Y19C), a G to $\mathrm{T}$ transversion of $\mathrm{nt} 244$ that predicted a valine to phenylalanine substitution at residue 82 (V82F), a T to C transition of nt 296 that predicted a valine to alanine replacement at residue 99 (V99A), a C to $\mathrm{T}$ transition of $\mathrm{nt} 311$ that predicted an alanine to valine substitution at residue $104(104 \mathrm{~V})$, and a $G$ to $A$ transition of nt 673 that predicted a glycine to serine replacement at residue 225 (G225S); a nonsense mutation, a C to $T$ transition of $\mathrm{nt} 745$ that predicted a glutamine to termination signal in codon 249 (Q249X); a frameshift mutation, the insertion of an adenine after cDNA nt 633 in codon 212 that caused a frameshift and predicted a premature stop at codon 214 (633ins A); two splicing mutations, a gt to at transition of the $5^{\prime}$ donor splice site of intron $2\left(\mathrm{IVS}^{+1}\right)$ and the deletion of an adenine in the +3 or $+45^{\prime}$ donor splice site (gtaag to gtag) of intron 9 (designated IVS $9^{\Delta A+4}$ ).

In addition to the new mutations, four previously reported missense mutations were identified, T62A, A66V, C73R, and T228M. A total of 34 of the 40 mutant alleles in the 20 CEP patients studied were detected (Table II). In 14 of the 20 patients, both mutant alleles were identified. Presumably, the six undetected mutations involved lesions such as gene deletions, promoter mutations, or other splicing defects. The allele frequencies of the 14 mutations in the 20 patients studied here, as well as among all reported CEP patients are shown in Table III. The C73R and L4F mutations were the most frequent with

( $A 9 A)$, an A to $\mathrm{G}$ transition of nt $56(Y 19 C)$, and a $\mathrm{G}$ to A transition at the $5^{\prime}$ donor splice site of intron $2\left(I V S 2^{+1}\right) ;(B)$ an exon 4 mutation, a $\mathrm{G}$ to $\mathrm{T}$ transversion of $\mathrm{nt} 244(\mathrm{~V} 82 \mathrm{~F}) ;(C)$ a single nucleotide insertion and deletion in exon 9, an insertion of an adenine after nt 633 in exon 9 (633ins $A$ ), and the deletion of an adenine from the $5^{\prime}$ donor splice site of intron $9\left(I V S 9^{\Delta \mathrm{A}+4}\right) ;(D)$ two exon 5 lesions, a $\mathrm{T}$ to $\mathrm{C}$ transition of nt $296(V 99 A)$ and a $C$ to $\mathrm{T}$ transition of nt $311(A 104 \mathrm{~V})$; and $(E)$ two exon 10 mutations, a G to A transition of nt $673(G 225 S)$ and a C to $\mathrm{T}$ transition of $\mathrm{nt} 745$ ( $Q 249 X)$. 
Table II. Genotype-Phenotype Correlations in Unrelated CEP Patients

\begin{tabular}{|c|c|c|c|c|c|}
\hline Proband* & Age & Sex & Ancestry & Disease severity ${ }^{\ddagger}$ & Genotype ${ }^{5}$ \\
\hline & $y r$ & & & & \\
\hline 1 & 17 & $\mathbf{M}$ & Scottish, Irish/German & Mild & C73R/A66V \\
\hline 2 & 17 & $\mathbf{M}$ & Romanian & Moderately severe & $\mathrm{C} 73 \mathrm{R} / \mathrm{T} 228 \mathrm{M}$ \\
\hline 3 & 19 & $\mathbf{M}$ & Japanese & Mild & T62A/Q249X \\
\hline 4 & 58 & $\mathbf{F}$ & African Black & Moderate & V99A/633InsA \\
\hline 5 & $5 \mathrm{mo}$ & $\mathbf{F}$ & Cree Indian & Severe/Deceased, HF & C73R/C73R \\
\hline 6 & 9 & $\mathrm{~F}$ & English & Severe, TD, TR & C73R/ \\
\hline 7 & 23 & $\mathbf{M}$ & English & Moderately severe & L4F/C73R \\
\hline 8 & 13 & $\mathrm{~F}$ & Alaskan Indian & Moderate & C73R/A104V \\
\hline 9 & 9 & $\mathbf{M}$ & English & Moderate & C73R/ \\
\hline 10 & 14 & $\mathbf{F}$ & German, Hungarian/Swedish & Moderate & $\mathrm{C} 73 \mathrm{R} /$ \\
\hline 11 & 40 & $\mathbf{F}$ & English, Irish/Polish & Mild & G225S/T228M \\
\hline 12 & 28 & $\mathbf{M}$ & English & Moderate & G225S/ \\
\hline 13 & 9 & $\mathbf{F}$ & Italian & Mild & L4F/V82F \\
\hline 14 & 10 & $\mathbf{M}$ & English & Severe, TD, TR & $\mathbf{L 4 F} /$ \\
\hline 15 & 3 & $\mathrm{~F}$ & Northern European & Moderate & LAF/IVS $^{+1}$ \\
\hline 16 & 18 & $\mathbf{M}$ & Indian & Mild & IVS9 $9^{\Delta A+4} /$ TVS9 $^{\Delta A+4}$ \\
\hline 17 & 49 & $\mathbf{F}$ & Swedish & Very mild & IV $2 S^{+1 /}$ \\
\hline 18 & 15 & $\mathbf{M}$ & English/Irish & Severe, TD & Y19C/G225S \\
\hline 19 & Stillborn & $\mathbf{F}$ & Belgian & Severe, HF & C73R/C73R \\
\hline 20 & 1 & $\mathbf{M}$ & Hispanic & Severe, HF, TD & C73R/C73R \\
\hline
\end{tabular}

* Probands 1-11 were previously reported (8) and the clinical and biochemical features of proband 19 were described (39). No proband was known to be consanguineous. ${ }^{\ddagger} \mathrm{TD}$, transfusion dependent; HF, hydrops fetalis; TR, chronic transfusion therapy to suppress erythropoiesis. ${ }^{8}$ Mutations described in text in boldface type. When known, ancestry of mutation indicated by backslash corresponding to respective genotype.

32.5 and $10.0 \%$, respectively, of the 40 alleles studied here, and 26.6 and $9.4 \%$ of the 64 CEP alleles reported here and elsewhere $(7,8,18-20)$.

Prokaryotic expression of the URO-synthase mutations. To

Table III. Allele Frequency of URO-Synthase Mutations Causing CEP

\begin{tabular}{|c|c|c|c|}
\hline \multirow[t]{2}{*}{ Type of mutation } & \multicolumn{2}{|c|}{$\begin{array}{l}\text { Number (and } \\
\text { percentage) of } \\
\text { alleles of } 40 \mathrm{CEP} \\
\text { alleles studied }\end{array}$} & \multirow[t]{2}{*}{$\begin{array}{l}\text { Percentage of all } \\
\text { CEP mutant } \\
\text { alleles studied* } \\
\text { (64 alleles) }\end{array}$} \\
\hline & $n$ & $\%$ & \\
\hline \multicolumn{4}{|l|}{ Missense mutations } \\
\hline C73R & $13^{\circ}$ & 32.5 & 26.6 \\
\hline $\mathrm{L} 4 \mathrm{~F}$ & 4 & 10 & 9.4 \\
\hline G225S & 3 & 7.5 & 4.7 \\
\hline $\mathrm{T} 228 \mathrm{M}$ & 2 & 5 & 4.7 \\
\hline \multicolumn{4}{|c|}{$\begin{array}{l}\text { Y19C, T62A, A66V, } \\
\text { V82F, V99A, } \\
\text { A104V, Q249X }\end{array}$} \\
\hline \multicolumn{4}{|l|}{ Frameshift mutation } \\
\hline 633insA & 1 & 2.5 & 1.6 \\
\hline \multicolumn{4}{|c|}{ Splicing defect mutations } \\
\hline IVS2 $^{+1}$ & 2 & 5 & 3.1 \\
\hline IVS9 $9^{\Delta A+4}$ & 2 & 5 & 3.1 \\
\hline Unknown alleles & 6 & 15 & 17.2 \\
\hline
\end{tabular}

* References 7, 8, 18-20. further characterize the URO-synthase mutations, pKK-UROS expression vectors for each of the newly identified exonic mutations were constructed, sequenced, and expressed in $E$. coli. Table IV shows the mean and range of URO-synthase activity for the expressed normal allele and each mutant allele. Only the missense mutations V82F, V99A, and A104V had mean residual activities that were $>3 \%$ of the expressed mean normal activity. Notably, the V82F allele expressed $35.8 \%$ of that expressed by the normal allele. However, incubation of the expressed activity at $37^{\circ} \mathrm{C}$ revealed that the V82F activity was

Table IV. Expression of URO-Synthase in E. coli

\begin{tabular}{lrcc}
\hline & \multicolumn{2}{c}{$\begin{array}{c}\text { URO-synthase activity } \\
\text { (U/mg)* }\end{array}$} & \\
\cline { 2 - 3 } \multicolumn{1}{c}{ Construct } & \multicolumn{1}{c}{ Mean } & Range & $\begin{array}{c}\text { Percentage of mean } \\
\text { normal level }\end{array}$ \\
\hline pKK223-3 & 1.91 & $0.00-3.47$ & - \\
pKK-UROS & 73.68 & $63.18-87.10$ & 100 \\
pKK-UROS-L4F & 3.38 & $3.39-4.48$ & 1.8 \\
pKK-UROS-Y19C & 2.69 & $1.62-3.46$ & 1.1 \\
pKK-UROS-V82F & 27.58 & $18.34-39.36$ & 35.8 \\
pKK-UROS-V99A & 5.93 & $3.61-8.23$ & 5.6 \\
pKK-UROS-A104V & 7.44 & $3.63-10.55$ & 7.7 \\
pKK-UROS-633insA & 2.78 & $1.47-3.79$ & 1.2 \\
pKK-UROS-G225S & 2.79 & $0.55-4.25$ & 1.2 \\
pKK-UROS-Q249X & 2.71 & $1.65-3.31$ & 1.1 \\
& & & \\
\hline
\end{tabular}

* Mean and range of activities for duplicate assays of three independent experiments, induced for $3 \mathrm{~h}$ with $5 \mathrm{mM}$ isopropylthiogalactoside. 


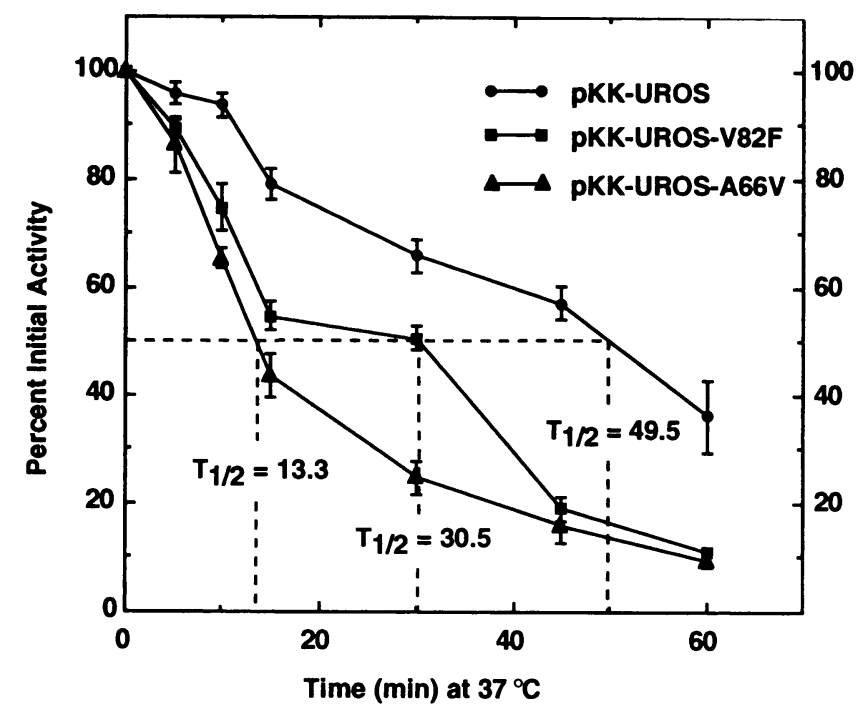

Figure 2. Thermostability of the URO-synthase activity expressed by pKK-UROS, pKK-UROS-V82F, and pKK-UROS-A66V (8) in E. coli. Cell extracts were incubated at $37^{\circ} \mathrm{C}$ for the indicated times and the URO-synthase activities were assayed. The results are expressed as the percentage of initial activity. Each value represents the average of triplicate determinations.

less stable than the normally expressed enzyme, the half-lives being 30.5 and $49.5 \mathrm{~min}$, respectively (Fig. 2). The thermostability of the $\mathrm{V} 82 \mathrm{~F}$ enzyme at $37^{\circ} \mathrm{C}$ and $60 \mathrm{~min}$ was similar to that of the previously reported V66A allele which expressed significant residual activity ( $15 \%$ of normal) in $E$. coli $(8)$.

Analysis of the URO-synthase splicing mutations. The putative splicing mutations (IVS2 ${ }^{+1}$, IVS9 ${ }^{\Delta \mathrm{A}+4}$, and V82F) were characterized by sequencing the URO-synthase RT-PCR products and determining their relative abundance in the respective lymphoid cell lines. Two RT-PCR products were present in the IVS2 ${ }^{+1} /$ L4F lymphoid cells, a normal product of $937 \mathrm{bp}$, and a smaller 848-bp product in which the entire exon 2 was deleted (Fig. $3 \mathrm{~A}$ ). That the IVS2 $2^{+1}$ allele did not produce any normalsized URO-synthase transcripts was indicated by the absence of detectable AvalI digestion fragments. Two URO-synthase RT-PCR products were present in the IVS $9^{\Delta A+4} /$ IVS $^{\Delta A+4}$ lymphoid cells, a normal product of $937 \mathrm{bp}$, and a smaller 838bp product in which sequencing revealed that the entire exon 9 was deleted (Fig. $3 \mathrm{~B}$ ). Radiolabeling of the RT-PCR products from three independent experiments revealed that $73.5 \%$ (range $69.0-77.9 \%$ ) of the IVS $9^{\Delta \mathrm{A}+4} /$ IVS $^{\Delta \mathrm{A}+4}$ RT-PCR products had the exon 9 deletion. Two URO-synthase RT-PCR products were present in L4F/V82F lymphoid cells, a normal product of $937 \mathrm{bp}$, and a smaller 840 -bp product in which sequencing revealed that the entire exon 4 was deleted (Fig. $3 C$ ). Radiolabeling of the EcoRI-digested RT-PCR products from three independent experiments revealed that $53.8 \%$ (range $48.7-56.2 \%$ ) of the RT-PCR products from the V82F allele had the exon 4 deletion.

Genotype-phenotype correlations in unrelated CEP patients. Identification and expression of both URO-synthase mutations in 13 of the 20 CEP patients permitted the estimation of their relative residual activities for genotype-phenotype comparisons. Each patient was classified as mild, moderate, or severely affected based on a review of their clinical history
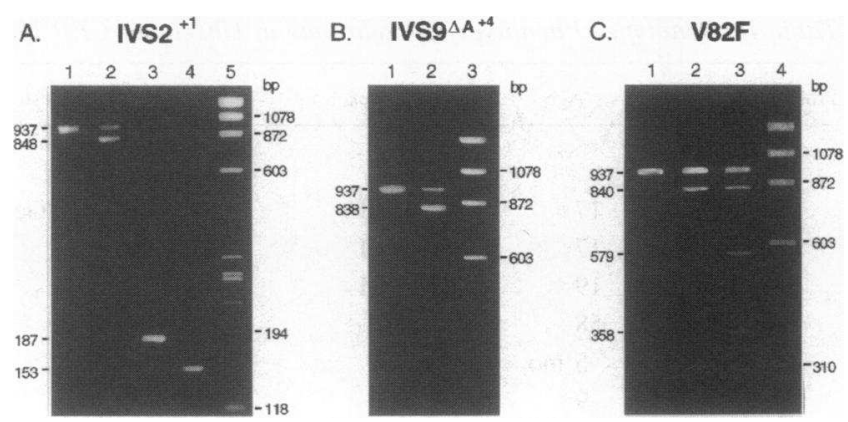

Figure 3. Analysis of the Splicing Mutations. Agarose gel electrophoresis and ethidium bromide staining of URO-synthase RT-PCR products from total lymphoid mRNA of patients with the L4F/IVS2 $2^{+1}$, IVS9 $9^{\Delta \mathrm{A}+4} / \mathrm{IVS}^{\Delta \mathrm{A}+4}$, and L4F/V82F genotypes as described in the text. $(A) \mathrm{IVS}^{+1}: \mathrm{RT}$-PCR products from a normal individual (lane 1 ) and the L4F/IVS $2^{+1}$ patient (lane 2) amplified with primers WX169 and WX174. Note the presence of the normal $937 \mathrm{bp}$ and exon 2 deleted 848-bp products in lane 2. After AvalI digestion of the normal and L4F/ IVS2 ${ }^{+1}$ RT-PCR products amplified with primers WX173 and WX3, the 187-bp abnormal product was not cleaved (lane 3 ), whereas the normal product was completely digested (lane 4 ), indicating that the IVS2 ${ }^{+1}$ allele did not encode any detectable normal transcripts. Lane 5 contained HaeIII-digested $\Phi$ X174 DNA. (B) IVS $9^{\triangle A+4}$ :RT-PCR products amplified with WX169 and WX174 from a normal individual (lane 1) and the IVS9 ${ }^{\triangle \mathrm{A}+4} /$ IVS $^{\triangle \mathrm{A}+4}$ patient (lane 2 ). Note the presence of the normal 937 bp and exon 9 deleted 838-bp products (lane 2). Lane 3 contained HaeIII-digested $\Phi$ X174 DNA. $(C)$ V82F: RT-PCR products from a normal individual (lane 1 ) and the L4F/V82F patient (lane 2) amplified with primers WX169 and WX174. After EcoRI digestion of the amplification products, a portion of the normally spliced 937-bp product which contained the EcoRI-cleavable V82F mutation was digested to 358-bp and 579-bp fragments. Lane 4 contained HaeIII-digested $\Phi$ X174 DNA.

and/or a recent examination by one of us (R. J. Desnick). Homoallelism for the most common allele, C73R, was associated with nonimmune hydrops fetalis and/or transfusion dependency from birth, as evidenced by the phenotypes of patients 5,19 , and 20 . Heteroallelism of C73R with a mutation that expressed little, if any, residual activity ( 8 and Table IV) also resulted in a severe or moderately severe phenotype (e.g., patients 2,7 , and 15 ). In contrast, patients heteroallelic for mutations that expressed residual activity (e.g., C73/A66V, L4F/ $\mathrm{V} 82 \mathrm{~F}$, and $\mathrm{T} 62 \mathrm{~A} / \mathrm{Q} 249 \mathrm{X}$ ) were milder, even if one of the alleles expressed no activity (8).

\section{Discussion}

In this communication, the 10 new and 4 previously reported mutations in the URO-synthase gene were detected in genomic DNA from 20 unrelated CEP patients using biotinylated primers to amplify each exon and adjacent exon-intron junctions, and separate single strands for direct solid phase sequencing. To facilitate mutation detection, each of the four sequencing reactions for each exon from a series of patients was electrophoresed in adjacent lanes so that mutations could be readily detected by pattern recognition. This mutation detection strategy identified 10 new lesions including six missense mutations, a nonsense mutation, a one-base insertion, and two splicing defects. The point mutations were readily detected as isolated single bands in different sequencing reactions, whereas the insertion and de- 
letion altered the positions of the nucleotides in all four reactions (see Fig. $1 \mathrm{D}$ ). In this way, the entire coding region and all intron/exon boundaries from each patient were rapidly sequenced and any lesions were detected by pattern recognition, rather than by completely reading the nucleotide sequence for each patient.

Since all exons and intron/exon boundaries must be sequenced to identify all possible disease-causing mutations in each allele, the direct sequencing strategy provided a single, efficient approach for mutation analysis and sequencing. This direct sequencing strategy proved more rapid and efficient for mutation detection in this large gene containing 10 exons encoding 265 residues than mutation detection methods such as the single strand conformation polymorphism technique (28), heteroduplex analysis (29), or the use of denaturing gradient gel electrophoresis (30), each of which requires one round of mutation detection followed by sequencing (e.g., 20). This amplification and sequencing strategy has proven efficient for mutation analysis in this gene, as well as for others studied in this laboratory $(31,32)$.

8 of the 10 new mutations were single base substitutions. Only the G225S lesion occurred at a CpG dinucleotide, a mutational "hot spot" due to deamination of methylcytosine to thymidine $(33,34)$. During the course of this investigation, the L4F mutation was reported independently by Boulechfar et al. (20). Mutations L4F, Y19C, V82F, and G225S markedly altered the nature of the encoded amino acid (e.g., charge, size, etc.), whereas mutations V99A and A104V substituted isofunctional residues. Of note, expression of the missense mutations revealed that those that altered charge, size, or hydrophilicity had no activity, or very low levels of residual activity, whereas isofunctional substitutions had detectable residual activities. Of interest, the V82F lesion expressed $\sim 36 \%$ of expressed normal activity. However, the V82F residual activity was inactivated in vitro at $37^{\circ} \mathrm{C}$ at a rate about twice that of the normal expressed enzyme, presumably reflecting the decreased stability of this mutant protein in vivo. The nonsense lesion Q249X predicted premature truncation of the normal 265 amino acid polypeptide, deleting the terminal 17 residues of the enzyme. Expression of this mutation resulted in little, if any, detectable activity. The 633ins A frameshift occurred in codon 212 and predicted different amino acids in residues 212 and 213 , and premature truncation of the remaining 52 carboxy-terminal amino acids. Expression of the 633insA lesion resulted in very little, if any, activity.

The IVS2 ${ }^{+1}$, IVS $9^{\Delta A+4}$, and V82F mutations all involved the 5 ' donor splice consensus sequence, $\mathrm{G} / \mathrm{gtaag}(35,36)$. The IVS2 ${ }^{+1}$ lesion occurred at invariant position 1 of intron 2 , a mutation that typically results in exon skipping (37). Analysis of the RT-PCR products from the IVS $2^{+1} / \mathrm{L} 4 \mathrm{~F}$ patient by AvalI digestion (which would only cleave the normal sequence) did not digest any normally sized transcripts, indicating that all the transcripts encoded by the IVS2 $2^{+1}$ allele were aberrant (Fig. 3 $A$ ). In contrast, the adenine deletion in the +3 or +4 position of the intron 9 consensus sequence resulted in two URO-synthase transcripts (Fig. $3 B$ ). The shorter, exon 9 deleted transcript represented $\sim 73.5 \%$ of the radiolabeled RT-PCR products encoded by this allele. Thus, the IVS $2^{+1}$ allele expressed no functional enzyme, whereas the IVS9 ${ }^{\Delta A+4}$ allele produced $\sim 25 \%$ normal transcripts encoding the active enzyme monomer. Of note, the V82F mutation, which substituted a $C$ to $G$ in the most $3^{\prime}$ nucleotide of exon 4 , altered the $5^{\prime}$ splice consensus sequence and resulted in abnormal splicing in $\sim 54 \%$ of the transcripts encoded by this allele. Thus, the V82F single base substitution resulted in two lesions, about half the transcripts were aberrantly spliced, while the remainder encoded a missense mutation which had $\sim 35 \%$ of normal activity (albeit thermolabile) when expressed in $E$. coli. A similar exonic lesion which caused alternative splicing of the $\alpha 5$ (IV) collagen gene was previously identified in a patient with Alport syndrome (38).

The identification of these mutations further expands the molecular heterogeneity of the URO-synthase mutations causing CEP. To date, a total of 14 different mutations has been identified in studies of 32 unrelated CEP patients. The C73R mutation was the most common CEP allele, occurring in $26.6 \%$ of all CEP alleles studied $(7,8,18-20)$. The LAF allele also was common, occurring in $\sim 10 \%$ of all CEP patients studied. Expression of these mutations in $E$. coli provided the opportunity to correlate genotype, predicted residual activity, and disease severity. Of the 20 patients studied, both alleles were identified in 14, permitting initial genotype/phenotype correlations. The three CEP patients who were homoallelic for C73R were severely affected, having hydrops fetalis and requiring intrauterine transfusions (patient 20), being stillborn (patient 19), or transfusion dependent, expiring at 5 mo (patient 5 ). The clinical phenotypes of these three patients suggest that homoallelism for C73R produces insufficient activity to sustain life, consistent with the fact that the C73R mutation had little, if any, activity when expressed in $E$. coli. $(8,20)$. In contrast, homoallelism for the IVS $9^{\triangle \mathrm{A}+4}$ mutation resulted in a mild phenotype, since $\sim 25 \%$ of the transcripts encoded by this allele were normal.

As no other patients were homoallelic for their lesions, the respective phenotype depends on the amount of residual activity contributed by each mutant allele. Since the C73R mutation encodes negligible activity, the four patients heteroallelic for C73R provide information on the effects of the L4F, A66V, A104V, and T228M alleles. The C73R/L4F patient was not transfusion dependent, but was moderately severe, consistent with the fact that the L4F allele expressed relatively little residual activity in $E$. coli (Table IV). In contrast, the patients heteroallelic for the A66V, A104V, and T228M alleles had moderate to mild (C73R/A66V) phenotypes, consistent with the expression of sufficient residual activity to produce adequate heme to avoid transfusion dependence. Similarly, patients with a single allele that expressed significant activity in $E$. coli might be expected to have milder phenotypes. However, the expressed residual activity must be assessed for its relative stability. For example, the patient with the L4F/V82F might be expected to be mild, since the V82F allele had $\sim 36 \%$ of expressed normal activity. However, when the V82F residual activity was incubated at $37^{\circ} \mathrm{C}$, the mutant enzyme proved unstable. Thus, heteroallelism for $\mathrm{L} 4 \mathrm{~F}$ and $\mathrm{V} 82 \mathrm{~F}$ was consistent with the moderately severe phenotype of this patient. The presence of residual activity with relatively normal stability of the expressed enzyme would be consistent with a milder phenotype. Further analysis of the URO-synthase genotypes of these and other CEP patients should further delineate the molecular heterogeneity underlying CEP and provide additional genotype/phenotype correlations.

\section{Acknowledgments}

The authors wish to thank Dr. Kenneth H. Astrin and Raman Reddy for assistance in these studies and preparation of this manuscript, and the following physicians for providing patients specimens for these 
analyses: Drs. D. Bickers, J. Bloomer, R. R. Chilcote, A. E. Chudley, G. Evans-Jones, E. J. Fitzsimons, H. Gabert, Y. Igarashi, N. Korman, S. Kramer, M. Layton, T. Long, L. V. Maldergem, C. Pierach, N. R. Pimstone, C. Phebus, M. Poh-Fitzpatrick, J. Rank, I. Rosenthal, K. S. Ryatt, J. Saba, A. J. Sellett, C. R. Scott, P. V. Tishler, G. C. Topi, and W. Wong.

This research was supported in part by grants from the National Institutes of Health including a research grant ( 5 R01 DK26824), a grant from the National Center for Research Resources ( 5 M01 RR00071) for the Mount Sinai General Clinical Research Center, and a grant (5 P30 HD28822) for the Mount Sinai Child Health Research Center.

\section{References}

1. Kappas, A., S. Sassa, R. A. Galbraith, and Y. Nordmann. 1989. The porphyrias. In The Metabolic Basis of Inherited Disease. J. B. Wyngaarden and D. S. Fredickson, editors. McGraw-Hill Inc., New York. 1305-1365.

2. Desnick, R. J., and K. E. Anderson. 1991. Heme biosynthesis and its disorders: the porphyrias and sideroblastic anemias. In Hematology: Basic Principles and Practice. R. Hoffman, E. J. Benz, S. J. Shattil, B. Furie, and H. J. Cohen, editors. Churchill-Livingstone Inc., New York. 350-367.

3. Romeo, G., and E. Y. Levin. 1969. Uroporphyrinogen III cosynthase in human congenital erythropoietic porphyria. Proc. Natl. Acad. Sci. USA. 63:856863.

4. Nordmann, Y., and J. C. Deybach. 1982. Congenital erythropoietic porphyria. Semin. Liver Dis. 2:154-163.

5. Deybach, J. C., H. de Verneuil, N. Phung, Y. Nordmann, A. Puissant and B. Boffety. 1981. Congenital erythropoietic porphyria (Günther's disease) enzymatic studies on two cases of late onset. J. Lab. Clin. Med. 97:551-558.

6. Horiguchi, Y., T. Horio, M. Yamamoto, T. Tanaka, Y. Seki, and S. Imamura. 1989. Late onset erythropoietic porphyria. Br. J. Dermatol. 121:255-262.

7. Warner, C. A., H. W. Yoo, S. F. Tsai, A. G. Roberts, and R. J. Desnick 1990. Congenital erythropoietic porphyria: characterization of the genomic structure and identification of mutations in the uroporphyrinogen III synthase gene. Am. J. Hum. Genet. 47:(Abstr.) 83 .

8. Warner, C. A., H. W. Yoo, A. G. Roberts, and R. J. Desnick. 1992 Congenital erythropoietic porphyria: identification and expression of exonic mutations in the uroporphyrinogen III synthase gene. J. Clin. Invest. 89:693-700.

9. Battersby, A. R., C. J. R. Fookes, K. E. Gustafson-Potter, E. McDonald and G. W. J. Matcham. 1982. Biosynthesis of porphyrins and related macrocycles. Part 17. Chemical and enzymatic transformation of isomeric aminomethylbilanes into uroporphyrinogens: proof that unrearranged bilanes the preferred enzymatic substrate and detection of a transient intermediate. J. Chem. Soc. Perkin Trans I. 1:2413-2426

10. Battersby, A. R., C. J. R. Fookes, K. E. Gustafson-Potter, E. McDonald and G. W. J. Matcham. 1982. Biosynthesis of porphyrins and related macrocycles Part 18. Proof by spectroscopy and synthesis that unrearranged hydroxymethylbilane is the product from deaminase and substrate for cosynthase in the biosynthesis of uroporphyrinogen III. J. Chem. Soc. Perkin Trans. I. 1:2427-2444.

11. Moore, M. R., K. E. L. McColl, C. Rimington, and A. Goldberg. 1987 Congenital porphyria. In Disorders of Porphyrin Metabolism. M. M. Wintrobe, editor. Plenum Publishing Corp., New York. 213-226.

12. Poh-Fitzpatrick, M. B. 1986. The erythropoietic porphyrias. Dermatol. Clin. 4:291.

13. Kramer, S., E. Viljoen, A. M. Meyer, and J. Metz. 1965. The anemia of erythropoietic porphyria with the first description of the disease in an elderly patient. Br. J. Haematol. 11:666.

14. Kaufman, B. M., H. R. Vickers, J. Rayne, and T. J. Ryan. 1967. Congenita erythropoietic porphyria. Report of a case. Br. J. Haematol. 79:210.

15. Tsai, S. F., D. F. Bishop, and R. J. Desnick. 1987. Purification and properties of uroporphyrinogen III synthase from human erythrocytes. J. Biol. Chem. 262:1268-1273.

16. Tsai, S. F., D. F. Bishop, and R. J. Desnick. 1988. Human uroporphyrinogen III synthase; molecular cloning, nucleotide sequence, and expression of a full length cDNA. Proc. Natl. Sci. USA. 85:7049-7053.

17. Astrin, K. H., C. A. Warner, H. W. Yoo, P. J. Goodfellow, S. F. Tsai, and R. J. Desnick. 1991. Regional assignment of the human uroporphyrinogen
III synthase (UROS) gene to chromosome 10q25.2-q26.3. Hum. Genet. 87:1822.

18. de Verneuil, H., J. C. Deybach, B. Grandchamp, and Y. Nordmann. 1989. Coexistence of two point mutations in the uroporphyrinogen III synthase gene in one case of congenital erythropoietic porphyria. Blood. 74:105(Abstr.).

19. Deybach, J. C., H. de Verneuil, S. Boulechfar, B. Grandchamp, and Y. Nordmann. 1990. Point mutations in the uroporphyrinogen III synthase gene in congenital erythropoietic porphyria. Blood. 75:1763-1765

20. Boulechfar, S., V. D. Silva, J. C. Deybach, Y. Nordmann, B. Grandchamp, and $\mathrm{H}$. de Verneuil. 1992. Heterogeneity of mutations in the uroporphyrinogen III synthase gene in congenital erythropoietic porphyria. Hum. Genet. 88:320324.

21. Hultman, T., S. Ståhl, E. Hornes, and M. Uhlén. 1989. Direct solid phase sequencing of genomic and plasmid DNA using magnetic beads as solid support. Nucleic Acids Res. 17:4937-4946.

22. Anderson, M. A., and J. F. Gusella. 1984. Use of cyclosporin A in estab lishing Epstein-Barr virus-transformed human lymphoblastoid cell lines. In Vitro (Rockville). 20:856-858.

23. Sambrook, J., E. F. Fritsch, and T. Maniatis. 1989. Molecular Cloning: A Laboratory Manual. 2nd ed. Cold Spring Harbor Laboratory, Cold Spring Harbor, NY. 22-27.

24. Saiki, R. K., D. H. Gelfand, S. Stoffel, S. J. Scharf, R. Higuchi, G. T. Horn, K. B. Mullis, and H. A. Erlich. 1988. Primer-directed enzymatic amplification of DNA with a thermostable DNA polymerase. Science (Wash. DC). 239:487-491

25. Dynabeads Biomagnetic Separation System Technical Handbook: Molecular Biology. 1st ed. 1993. Dynal AS, Oslo, Norway.

26. Sanger, F., S. Nicklen, and A. R. Coulson. DNA sequencing with chainterminating inhibitors. 1977. Proc. Natl. Acad. Sci. USA. 74:5463-5467.

27. Gobinda, S., and S. Sommer. 1990. The "megaprimer" method of sitedirected mutagenesis. Biotechniques. 8:404-407.

28. Orita, M., Y. Suzuki, T., Sekiya, and K. Hayashi. 1989. Rapid and sensitive detection of point mutations and DNA polymorphisms using the polymerase chain reaction. Genomics. 5:874-879.

29. White, W. B., M. Carvalho, D. Derse, S. J. O'Brien, and M. Dean. 1992 Detecting single base substitutions as heteroduplex polymorphism. Genomics. 12:301-306

30. Lerman, L. S., S. G. Fischer, I. Hurley, K. Silverstein, and N. Lumelsky 1984. Sequence-determined DNA separation. Annu. Rev. Biophys. Bioeng. 13:399-423.

31. Chen, C. H., K. H. Astrin, G. Lee, K. E. Anderson, and R. J. Desnick. 1994 Acute intermittent porphyria: identification and expression of exonic mutations in the hydroxymethylbilane synthase gene. An initiation codon missense mutation in the housekeeping transcript causes "variant acute intermittent porphyria" with normal expression of the erythroid-specific enzyme. J. Clin. Invest. 94:19271937.

32. Eng, C. M., L. A. Resnick-Silverman, D. J. Niehaus, K. H. Astrin, and R. J. Desnick. 1993. Nature and frequency of mutations in the alpha-galactosidase A gene that cause Fabry disease. Am. J. Hum. Genet. 53:1186-1197.

33. Coulondre, C., J. H. Miller, P. J. Farabaugh, and W. Gilbert. 1978. Molecular basis of base substitution hotspots in Escherichia coli. Nature (Lond.) 274:775-780.

34. Youssoufian, H., H. H. Kazazian, Jr., D. G. Phillips, S. Aronis, G. Tsiftis, V. A. Brown, and S. E. Antonarakis. 1986. Recurrent mutations in haemophilia A give evidence for CpG mutation hotspots. Nature (Lond.). 324:380-382.

35. Shapiro, M. B., and P. Senapathy. 1987. RNA splice junctions of different classes of eukaryotes: sequence statistics and functional implications in gene expression. Nucleic Acids Res. 15:7155-7174.

36. Senapathy, P., M. B. Shapiro, and N. L. Harris. 1990. Splice junctions, branch point sites, and exons: sequence statistics, identification, and applications to genome project. Methods Enzymol. 183:252-278.

37. Sillence, D. O., A. A. Chiodo, P. E. Campbell, and W. G. Cole. 1991 Ehlers-Danlos syndrome type IV: phenotypic consequences of a splicing mutation in one COL3A1 allele. J. Med. Genet. 28:840-845.

38. Nomura, S., G. Osawa, T. Sai, T. Harano, and K. Harano. 1993. A splicing mutation in the $\alpha 5$ (IV) collagen gene of a family with Alport's syndrome. Kidney Int. 43:1116-1124.

39. Verstraeten, L., N. Van Regemorter, A. Pardou, H. de Verneuil, V. Da Silva, F. Rodesch, D. Vermeylen, C. Donner, J. C. Noël, Y. Nordmann, and A Hassoun. 1993. Biochemical diagnosis of a fatal case of Günther's disease in newborn with hydrops foetalis. Eur. J. Clin. Chem. Clin. Biochem. 31:121-128. 